\title{
O dever de resistir: sobre escolas, professores e sociedade*
}

\author{
The duty to resist: on schools, teachers and society
}

El deber de resistir: sobre escuelas, maestros y sociedad

\author{
GERT BIESTA**
}

$\diamond$

\begin{abstract}
RESUMO
Nas sociedades contemporâneas existem muitas expectativas sobre o que as escolas devem fazer. Estas incluem a instrumentalização de crianças e jovens para o mundo do trabalho, a sua transformação em cidadãos democráticos ou a criação de uma sociedade coesa e inclusiva. O que une essas expectativas é que elas se aproximam da escola como uma espécie de instrumento para resolver problemas da sociedade. A escola é tratada como tendo uma função para a sociedade e, portanto, como uma instituição que deve ser funcional e útil para ela. O perigo dessa maneira de pensar é que outras questões - como o que a escola deve cuidar ou proteger - desaparecem facilmente do campo de visão. Neste artigo, explora-se como se pode responder à pergunta sobre qual é a "tarefa" especial e exclusiva da escola, argumentando que esta não deve ser vista apenas como tendo uma função para a sociedade, mas também como tendo um dever importante de resistir às demandas que a sociedade deseja que sejam atendidas.
\end{abstract}

Palavras-chave: Educação. Resistência. Qualificação. Socialização. Subjetivação.

\begin{abstract}
In contemporary societies there are many expectations about what schools should do. These include equipping children and young people for the world of work, turning them into democratic citizens, or bringing about a cohesive and inclusive society. What unites such expectations is that they approach the school as a kind of instrument for solving societal problems. The school is treated as a function of society and thus as an institution that should be functional and useful for society. The danger with this way of thinking is that other questions - such as what it is that the school should take care of or stand for - easily disappear from sight. In this paper I explore how we might answer the question about the special and unique 'task' of the school, arguing that the school should not just be seen as a function of society but also has an important duty in resisting what society desires from it.
\end{abstract}

Keywords: Education. Resistance. Qualification. Socialization. Subjectification.

\section{RESUMEN}

En las sociedades contemporáneas hay muchas expectativas sobre lo que deberían hacer las escuelas. Esto incluye equipar a los niños y jóvenes para el mundo del trabajo, convirtirlos en ciudadanos democráticos o creando una sociedad cohesiva e inclusiva. Lo que une tales expectativas es que se acercan a la escuela como una especie de herramienta para resolver problemas sociales. La escuela se trata como tenendo una función para la sociedad y, por lo tanto, como una institución que debe ser funcional y útil para ella. El peligro de esta forma de pensar es que otras preguntas, como qué es lo que la escuela debe cuidar o representar, desaparecen fácilmente de la vista. En este artículo exploro cómo podríamos responder la pregunta sobre la "tarea" especial y única de la escuela, argumentando que la escuela no solo debe considersarse como tenendo una función para la sociedad sino que también tiene un deber importante para resistir a lo que la sociedad desea de ella.

Palabras clave: Educación. Resistencia. Calificación.Socialización. Subjetivación.

\footnotetext{
* O entendimento de que a educação está conectada com o dever de resistir vem do teórico da educação francês Philippe Meirieu. Ver seu ebook: Pédagogie: le devoir de résister (Education: the duty to resist; Educação: o dever de resistir, 2007).

**Professor de Educação no Departamento de Educação da Brunel University London.E-mail: gert.biesta@brunel.ac.uk
} 


\section{A HISTÓRIA DUPLA DA ESCOLA}

Para responder à questão sobre qual o papel ou posição que deveria ter a escola na sociedade de hoje, pode ser útil começar com uma breve história que pode ser caracterizada como dupla. Parte desta a vê como sendo uma função $d a$ e tendo um propósito para a sociedade. Aqui, ela é uma instituição que emerge quando a sociedade perde seu poder educativo, ou seja, quando não pode mais assumir que a nova geração simplesmente "pegará" tudo o que precisa saber e ser capaz de fazer apenas por ser parte da sociedade (MOLLENHAUER, 1983). Visto dessa perspectiva, pode-se afirmar que a sociedade tem expectativas legítimas sobre a escola porque esta surgiu precisamente para fazer algo pela sociedade.

Mas essa não é a única história. Uma segunda fala da escola como um lugar entre a casa e a rua, por assim dizer: a escola como um lugar de transição, onde não se está mais em casa, mas também ainda não se está no mundo real, o da produção econômica e dos processos políticos, por exemplo. Aqui, a escola é um lugar onde se pode praticar, tentar coisas sem que tudo tenha de ser perfeito (o que pode significar por essa perspectiva que a escola deve, por definição, estar concentrada na imperfeição (ver SIDORKIN, 2002). Nessa história, a escola é um tipo de lugar no meio do caminho, que, de certa forma, precisa estar protegido das demandas da sociedade para que seja possível praticar e tentar coisas (ver também MASSCHELEIN \& SIMONS, 2012).

Olhar para a escola em sua dupla história revela uma tensão em seu próprio tecido: uma tensão entre a necessidade de atender às demandas da sociedade e a necessidade de preservar-se destas. Pode-se dizer, portanto, que é um tipo de serva de dois senhores, como na famosa peça de Goldoni. Isso causa particulares desafios para professores, mas os bons geralmente sabem como encontrar equilíbrio entre as demandas dos dois mestres. Também sabem que a escolha pela criança não é contra a sociedade - ao contrário do que alguns proponentes dos antigos e contemporâneos métodos de educação centrados na criança parecem pensar (sobre isso, ver também OELKERS, 2005). A tarefa última da educação é ajudar as crianças e os jovens a estar no mundo (e estar lá de modo "adulto"; ver BIESTA, 2015a; 2015b).

O problema que se enfrenta hoje em muitos contextos educacionais é que a voz de um dos mestres - sociedade - se tornou muito mais alta e muito mais dominante que a outra, a voz que diz que a escola também tem algo para fazer que não é automática ou necessariamente útil para a sociedade. Como resultado de testes, avaliações e intervenções em curso no currículo, a partir de forças sociais específicas, frequentemente forças econômicas, encontra-se a escola em muitos países e contextos em sério desequilíbrio. Isso está acontecendo em tal extensão que se pode perguntar se a escola ainda pode ser uma escola ou se já foi transformada em algo completamente diferente - um lugar para trabalho e produção ao invés de um lugar de scholé, ou seja, de "tempo livre" ainda não determinado por demandas externas (ver MASSCHELEIN \& SIMONS, 2012; MEIRIEU, 2007).

A questão, então, é como se pode ser capaz de restaurar o equilíbrio entre as diferentes demandas projetadas sobre a escola. O modo que se aborda essa questão é perguntando o que a própria escola deveria significar, ou seja, qual interesse particular a escola deveria reivindicar como exclusivamente seu. Essa questão é importante porque, como diz o ditado, se não significa nada, pode significar qualquer coisa. O que, então, a escola deveria significar?

\section{APRENDiZAGEM? DESENVOLVIMENTO? FORMAÇÃo?}

Aqui se encontra outro problema, porque não faltam respostas para essa questão. Ao contrário, quando se questiona ou apenas se olha ao redor, parece haver bastante clareza sobre o que a escola é e sobre o que ela poderia ser. A seguir, discutem-se três possíveis respostas mais ou menos proeminentes para a questão em maiores detalhes. São estas: aprendizagem, desenvolvimento e formação.

Aprendizagem, como se tem dito em outros escritos (ver, por exemplo, BIESTA, 2006; 2013; 2015c), vem se tornando a mais popular e influente opção. Pode-se ver isso refletido na linguagem da aprendizagem na educação, ou seja, no frequente aparecimento de noções como "ambientes de aprendizagem", "comunidades de aprendizagem", "aprendizagem personalizada", "aprendizagem colaborativa", "aprendendo a aprender", "aprendizagem ao longo da vida" e assim por diante. A segunda noção, desenvolvimento, tem se tornado também bastante popular e influente. Não se pode apenas considerar a ideia geral de que a educação é sobre dar suporte ao desenvolvimento da criança. A noção de desenvolvimento também desempenha um papel no argumento de que o foco da educação é a criatividade e a expressão e para a ideia de que deve tornar possível para as crianças desenvolverem todos os seus talentos e realizarem seu "pleno potencial".

A noção de formação é menos popular, se for conhecida. Em alguns países e linguagens, é visto como um conceito (mais) antigo e, em certa medida, mesmo antiquado e ultrapassado. No entanto, há algo que se gosta sobre a ideia de formação, na medida em que se entende a educação como um encontro entre criança e mundo, no qual e através do qual a criança adquire uma certa 
"forma". Esse encontro não pode ser entendido como a simples impressão da forma do mundo na criança. É um encontro no real sentido da palavra, em que algo acontece na criança e no mundo.

Então é a aprendizagem, o desenvolvimento ou a formação o interesse que a escola deve representar?

\section{O “APRENDERISMO” NA EDUCAÇÃO ${ }^{1}$}

Uma linha importante do trabalho realizado pelo autor na última década tem sido o de documentar a ascensão do que em alguns lugares foram referidos como a "nova linguagem da educação" e o subsequente "aprenderismo" (learnification) do discurso e da prática educacional (ver BIESTA, 2010). O crescimento da linguagem da aprendizagem na pesquisa, política e prática em educação é visível em grande número de expedientes discursivos, que incluem a tendência de se referir como "aprendentes" aos pupilos, estudantes, crianças e adultos; como "apoiadores de aprendizagem" ou "facilitadores de aprendizagem" aos professores; como "ambientes de aprendizagem", "lugares para aprendizagem" ou "comunidades de aprendizagem" às escolas, e na redesignação do campo da educação de adultos no sentido de uma "educação ao longo da vida" (para detalhes, ver BIESTA, 2006; 2013; $2015 \mathrm{c}$ ). O problema não é - ou não é imediatamente (ver BIESTA, 2015c) - com a aprendizagem em si mesma, mas sim com a linguagem da aprendizagem. A principal preocupação aqui tem a ver com o fato de que a linguagem da aprendizagem é demasiadamente limitada como uma linguagem educacional.

Uma maneira rápida para indicar qual é o problema é dizer que o objetivo da educação nunca é que as crianças e jovens aprendam - e é útil parar aqui e considerar as muitas instâncias da política, pesquisa e prática diária da educação nas quais não muito mais do que isso está sendo dito -, mas sim que crianças e jovens aprendam alguma coisa, que aprendam isso por um motivo e que aprendam isso de alguém. Aqui reside a diferença fundamental entre a linguagem da aprendizagem, que, em certo sentido, é vazia de conteúdo e propósito, e a linguagem da educação, que sempre precisa se engajar com questões de conteúdo, propósito e relações.

Não se quer afirmar que, quando acontece aprendizagem na educação, não há conteúdo, que relações não desempenham nenhum papel e que todo o processo é sem objetivo ou direção. Ainda assim, sugere-se que, se houver apenas a linguagem da aprendizagem para falar

\footnotetext{
${ }^{1}$ Nota do tradutor: Gert Biesta criou o termo 'learnification' em inglês. Este foi traduzido como 'aprenderismo' em português por Guilherme, A. e Freitas, Ana L. S.; "Paulo Freire e Gert Biesta: um diálogo fecundo sobre a educação para além da facilitação da aprendizagem, Inter-ação, v. 42, n. 1, p. 69-86, 2017.
}

em e sobre educação, esta poderá muitas vezes esquecer as questões educacionais sobre conteúdo, propósitos e relações. Isso, na maioria das vezes, significa que decisões que devem ser tomadas por educadores ocorrem em outros lugares, na política, entre os elaboradores do currículo ou editores de livros didáticos, em um sistema global de avaliação etc.

\section{CONCENTRANDO-SE NA QUESTÃo DOS PROPÓSITOS}

Das três - conteúdo, propósito e relações -, a questão do propósito é central e fundamental porque, se não se sabe o que se busca alcançar com os empreendimentos educacionais, não se tem critério para decidir que tipo de conteúdo deve ser posto em prática, nem como as relações devem ser utilizadas e que tipos de modelos educacionais são mais adequados. Dizer que a questão do propósito é central e fundamental não é fazer qualquer reivindicação sobre quem deve enunciar o propósito do empreendimento educacional - há uma variedade de opções, embora os professores precisem desempenhar um papel importante nisso. Também não é sugerir que o propósito do empreendimento educacional deve ser formulado como um objetivo claro ou como uma meta que deveria ser cumprida ou alcançada - que é o problema com a ideia contemporânea de "resultados de aprendizagem". O objetivo de uma atividade dá significado e direção a esta, mas isso pode ser feito de diferentes maneiras e com mais ou menos especificidade.

O ponto mais importante a respeito do propósito da educação é que esta não está orientada para somente um propósito, mas que, na realidade, em todas as instâncias da educação, três diferentes propósitos - ou melhor, domínios de propósito - estão "em jogo". A ideia aqui (desenvolvida em maiores detalhes em BIESTA, 2010) vem da simples observação de que educação sempre é sobre a apresentação e aquisição de algo (conhecimento, habilidades, caráter) e, nesse sentido, sempre orientada para a qualificação de crianças e jovens. Trata-se de dar-lhes acesso ao conhecimento, habilidades e caráter que lhes permitam fazer alguma coisa, seja no sentido estrito de se tornar qualificado para o mundo do trabalho ou para uma atividade ou profissão específica, seja no sentido muito mais amplo de se tornar qualificado para a vida nas complexas sociedades modernas. Alguns argumentariam que isso é tudo o que há sobre educação e que isso é tudo no que a educação deveria estar concentrada - que deveria se restringir ao "básico", aos "fatos" e deixar questões difíceis que têm a ver com valores a cargo da família ou da comunidade. Mas, infelizmente essas coisas não são facilmente separáveis. 
Mesmo se a escola se restringisse apenas aos fatos, estes, afinal, já estariam comunicando fortes mensagens sobre um desejável modo de vida e de viver juntos, mesmo que se acredite na possibilidade de se manter separados fatos e valores. Isso mostra que é inevitável que toda educação, quando organizada, também se dedique à socialização, à comunicação e ao fornecimento do acesso às tradições, culturas, modos de ser e agir às crianças e aos jovens. Por um lado, isso é o que acontece sempre que a educação se estabelece - e não apenas através do ensino, do currículo e da pedagogia, mas também através da arquitetura escolar, do lugar da escola na sociedade etc. Por outro lado, pode-se dizer que isso é parte da tarefa da escola dedicada à socialização. Novamente, pode-se pensar na socialização profissional, isto é, apresentando as formas de ser e de fazer de um trabalho ou profissão. Mas educação para a cidadania, educação religiosa, educação ambiental e "educações" similares também não são apenas sobre conhecimento, habilidades e caráter, mas sobre comunicação e inclusão em tradições e culturas. Assim, a educação ajuda os jovens a se orientar no mundo, a encontrar seu lugar, o que também afeta quem eles se tornam - sua formação como indivíduos e a aquisição de certa identidade.

Juntamente com a qualificação e com a socialização, sugere-se que a educação deva sempre ter um interesse no que, com um termo técnico, trata-se neste trabalho como subjetivação. Isso tem a ver com a possibilidade de que crianças e jovens não adotem apenas uma identidade particular, não sejam apenas parte de comunidades e tradições específicas, apenas objetos das intenções e ações de outras pessoas, mas existam como (um) sujeito por direito próprio, capaz de suas próprias ações e disposto a assumir a responsabilidade pelas consequências dessas ações. Educação, em outras palavras, nunca é apenas para qualificar crianças e jovens e oferecer-lhes um lugar particular na sociedade. A capacidade de assumir uma perspectiva crítica para com tradições, práticas, modos de fazer e de ser existentes, também se dá após sua saída da escola.

\section{DECISÕES ENQUANTO SE EDUCA}

Embora os três domínios de propósito possam ser distinguidos, não podem ser separados e estão sempre "em jogo" em tudo o que se faz na educação. Esses três domínios do propósito educacional podem ser descritos na forma do Diagrama de Venn, com três áreas parcialmente sobrepostas. Tal diagrama provê a descrição de uma concepção ampla do que é a educação - uma concepção que reconhece que a educação sempre precisa estar engajada com questões de conteúdo, tradição e liberdade do estudante como sujeito. É também útil a fim de tornar visível - ou se pode também dizer: a fim de mostrar o que dá errado - quando empreendimentos educacionais estão limitados a apenas um dos três domínios. Isso porque, nesse caso, os outros dois podem ser esquecidos, o que não significa que nada está acontecendo, mas que está fora do âmbito da responsabilidade dos educadores. Embora, como indicado anteriormente, o principal problema que muitos sistemas educacionais encontram hoje seja uma excessiva ênfase sobre o domínio da qualificação, o argumento apresentado aqui implica que as concepções de educação que focam exclusivamente a socialização ou a subjetivação são também unilaterais e, portanto, também problemáticas.

O desafio, portanto, não é apenas manter os três domínios em algum tipo de equilíbrio. É também sempre pensar e agir de um modo que remete às três dimensões - não apenas na prática, mas também na política e na pesquisa educacional. Isso significa que pesquisas que apenas procuram investigar como certas "intervenções" impactam o "desempenho acadêmico", sem perguntar qual é o efeito nos outros domínios, são completamente inúteis, isso porque nunca se quer simplesmente saber como se pode conduzir o desempenho acadêmico, mas sempre se precisa também saber o que isso implica nas ambições que se tem para os domínios da socialização e da subjetivação. Mais concretamente: se a pesquisa disser que o tema de casa não tem impacto significativo no desempenho acadêmico, isso não pode nunca ser a razão para se parar de dar dever de casa para as crianças e jovens. Talvez porque possa haver um motivo no domínio da, por exemplo, subjetivação, que justifica que o tema de casa - a situação em que a criança é responsável por realizar uma tarefa fora do olhar do professor - possa ser uma importante experiência educacional. A pesquisa que aborda de outra forma é simplesmente enganosa e não deve passar no exame da boa, significativa e útil pesquisa educacional.

O pensamento e a prática nas três dimensões também começam a revelar as complexidades mesmo das menores decisões e momentos de ação no trabalho do professor. Uma boa imagem para indicar a complexidade do ensino, vista a partir da perspectiva do caráter triplo do propósito educacional, é a do xadrez tridimensional em que três jogos completos são jogados em tabuleiros sobrepostos e em que as peças não apenas interagem horizontalmente, mas também verticalmente. Assim, um movimento no "jogo" da qualificação não apenas impacta o que acontece e pode acontecer lá, mas, ao mesmo tempo, "faz" algo nos "jogos" da socialização e da subjetivação, e vice-versa.

O motivo para entrar em detalhes aqui não é apenas mostrar as limitações da linguagem da aprendizagem como uma linguagem para a educação, mas também para realçar o papel e a necessidade da decisão na educação. Há 
uma primeira decisão permanentemente necessária sobre o que se procura alcançar em relação a cada um dos três domínios - o que significa que o currículo, não entendido como listas de conteúdos, mas como concepções para o empreendimento educacional, deve especificar tais ambições de modo que atenda às três dimensões. E há decisões necessárias sobre os mais apropriados meios para atingir o que se procura atingir. No que diz respeito ao último, é importante ver que isso não é uma questão da eficácia do que se faz, mas também do que se sugere chamar de qualidade educativa do que se faz.

Isso tem a ver com outro aspecto exclusivo da educação, que é o fato de que os estudantes não apenas aprendem a partir do que se diz, mas também a partir de como se faz. Significa que em tudo que se faz sempre é necessário se perguntar que tipo de mensagem se está comunicando e é preciso ter certeza de que tais mensagens são congruentes com os objetivos e ambições declarados dos empreendimentos educacionais. Essa questão novamente contém uma importante mensagem para a pesquisa educacional, nomeadamente que não pode se limitar a procurar o mais eficaz (e, para essa questão, eficiente) meio de fazer algo, mas sempre precisa considerar se o que é eficaz é também congruente com o que se procura alcançar, e isso em todos os três domínios. Embora o tema de casa possa não ser eficaz no que diz respeito a realizações específicas no domínio cognitivo, pode muito bem ser eficaz no que diz respeito a questões de responsabilidade e confiança.

Se questões sobre o que e sobre como já revelam a complexidade da decisão educacional, isso é ainda mais evidente com respeito a um terceiro problema que se torna visível quando se olha para a educação dessa maneira, que tem a ver com a questão do equilíbrio e das negociações. Embora a educação precise estar preocupada com os três domínios, não se pode fazer tudo em todos os domínios, ao mesmo tempo. Então, muitas vezes - e talvez sempre -, confronta-se com a questão sobre o que se está disposto a "desistir" (embora temporariamente) em um ou dois domínios a fim de atingir algo em um ou dois dos outros domínios. Essa não é uma questão abstrata que se pode resolver no âmbito do planejamento, mas algo que é preciso considerar para cada estudante individualmente.

Para destacar o papel essencial da decisão no ensino, não apenas mostrar a complexidade de ensinar como uma profissão - se for assumida a responsabilidade nos três domínios seriamente - mas também revelar que em educação não se podem evitar questões normativas. Decisões são, afinal de contas, não questões de fato, mas de valor, e, consequentemente, precisam ser orientadas por valores mais amplos, educacionais e preocupados com perspectivas sobre viver bem e viver bem juntos. A partir da decisão em educação, agora se passa para o que se pode chamar de decisões sobre educação.

\section{DECISÃO SOBRE EDUCAÇÃO: UM SENSO DE DIREÇÃO}

A questão que se deseja levantar aqui é sobre o tipo de valores e de pontos de referências que podem ser significativos para promover educação com um senso geral de direção. Já se mencionou que não há escassez de perspectivas sobre o que a educação é. Também, nesse nível "mais amplo" da discussão, tendese a encontrar ideias mais claras ao invés de uma falta delas. Na atmosfera educacional contemporânea há uma narrativa que é particularmente proeminente e repetida em parágrafos de abertura de documentos políticos em todo o mundo moderno. Apresenta-se essa história no que segue abaixo.

A primeira afirmação é que, ao contrário do que se era no passado, agora aparentemente se vive em uma sociedade e mesmo em um mundo que está mudando em um ritmo muito alto, o que está relacionado a desenvolvimentos como globalização, digitalização, individualização e assim por diante. Acrescida à alegação do alto ritmo da mudança está a afirmação de que aparentemente já não se sabe como será o futuro, então que o conhecimento que se tem hoje deverá ser rapidamente ultrapassado. Em algumas versões dessa narrativa, recebe-se a informação de que está se usando um sistema educacional do século XX - ou, até mesmo, do século XIX - para preparar crianças e jovens para o século XXI. E tudo isso, então, conduz à conclusão de que a educação precisa de uma revisão radical, de uma completa transformação. Não se deve mais aborrecer as crianças e os jovens com conhecimentos, particularmente não com fatos, porque o conhecimento estará ultrapassado antes que eles cresçam. E os fatos estarão armazenados em seus dispositivos digitais pessoais ao invés de precisarem preservá-los "em suas cabeças". O que se deve fazer é equipar as crianças e os jovens com um conjunto geral de habilidades - às vezes, chamadas de habilidades do século XXI - que lhes permitirá rápida e flexivelmente se ajustar ao desconhecido em rápidas mudanças de circunstâncias.

Versões dessa história são ubíquas nos documentos políticos sobre educação, mas também estão presentes na pesquisa e na prática educacional. Ainda a questão crítica e crucial é se essa história é verdadeira ou não. A sugestão que se faz é que essa narrativa é uma meia verdade, uma verdade que é precisa apenas em relação a alguns casos e situações - daí seu apelo ao senso comum -, mas que é completamente inadequada para outros cenários. É uma narrativa que corre o risco de ser um clássico exemplo de ideologia: uma verdade que esconde tanto 
quanto revela. E isso se torna problemático quando esta representa o quadro principal de referência para definir a direção para a educação. Então, onde essa narrativa está errada?

\section{MEIAS VERDADES E IDEOLOGIA}

Quando se considera a afirmação de que a sociedade, a vida moderna e o mundo estão mudando em um ritmo muito alto, pode-se de fato pensar em partes do mundo, aspectos da vida e domínios da vida em que esse é o caso. Nos domínios da economia, do mercado financeiro, do acesso à informação, podem-se apontar mudanças que ocorrem de fato de um modo sem precedentes (embora se deva acrescer: se o ritmo da mudança for sustentável). Mas o ponto que se deseja frisar aqui é que, se, para alguns, em algumas partes do mundo e com respeito a alguns aspectos de nossas vidas, há de fato mudanças e estas têm um ritmo acelerado; para outros, em outras partes do mundo, e com respeito a outros aspectos da vida, muito pouco mudou e muito pouco está mudando. Para um grande número de pessoas, há diariamente dúvidas se encontrarão água potável, se alimentarão suas famílias, se terão uma renda para tornar suas vidas sensivelmente mais seguras. Isso porque a sugestão de que tudo está mudando rápido, em todo lugar e para todos, é uma mentira - não obstante, uma mentira que serve a alguns, o que pode ser um importante motivo de sua constante repetição.

Portanto, não se sabe hoje como o futuro parecerá, e portanto, o conhecimento que se possui já está ultrapassado para o amanhã. Novamente, pode-se pensar nos domínios em que isso é verdade. $\mathrm{O}$ mundo do trabalho como se conhece hoje é, em alguns domínios, fundamentalmente diferente de como era no passado, e é provável que seja diferente no futuro. Mas não se deve tornar isso uma afirmação universal sobre todos os aspectos da vida de todas as pessoas e em todos os cantos do planeta. Ao contrário, há aspectos da vida que já se sabe muito bem como serão no futuro, porque são problemas que têm a ver com as mais duradouras dimensões da vida e de viver juntos, que não mudaram muito nos séculos e que podem continuar não mudando, mas, de certa forma, apenas serão mais urgentes. Daqui a 50 anos, ainda haverá a questão da democracia, isto é, a questão de como se consegue viver juntos, dado que todos são diferentes, e valorizar essas diferenças. Haverá ainda a questão de como se consegue sustentar a vida coletiva em um planeta com capacidade limitada para atender a todos os desejos que se projetam sobre ele. E poderá haver também a questão do cuidado, ou seja, a questão de como um cuida do outro, particularmente daquele que ainda não é - ou que não são mais - capaz de cuidar de si mesmo.

\section{REDEFININDO OS FUNDAMENTOS DA EDUCAÇÃO}

Em muitos países, elaboradores de políticas, políticos e formadores de opinião mantêm a narrativa de uma sociedade de rápida mudança e de um futuro desconhecido, argumentando que isso requer que a prioridade da educação seja sobreviver na economia global. Essa forma de pensar geralmente conduz a certa definição do que é assim chamado de "fundamentos" da educação. Estes se definem em termos de conhecimentos e habilidades úteis para o funcionamento da economia com referência ao mercado de trabalho e à competição - e para adaptações flexíveis às condições em permanente mudança. Como resultado, os sistemas educacionais no mundo todo estão cada vez mais parecidos.

À luz do que se tem dito até agora, afirma-se que se precisa de um quadro de referências mais amplo e diferente para a educação, no qual se incluam questões de democracia, ecologia e cuidado como pontos de orientação para o engajamento com a questão do que deve dar direção aos empreendimentos educacionais. Que se deve começar com questões de democracia, ecologia e cuidado. Isso porque estas têm a ver com questões existenciais que se enfrentam quando se tenta descobrir como se pode conseguir viver junto na pluralidade das formas humanas em um vulnerável e já significativamente exaurido planeta. Acredita-se que esses sejam os reais "fundamentos" para a educação contemporânea e para a educação do futuro.

Isso não significa, é claro, que a economia não importa, mas que o desafio é "fazer" economia diferentemente, de forma mais sustentável, cuidadosa e democrática. Também se sugere que deve ser questionado o foco sobre a competição - em que se está bem se se é parte do "time" vencedor, mas que se torna mais incômodo quando a mesa vira. Além de questionar também como cooperação e colaboração podem se tornar mais centrais na forma como se conduz a vida coletiva. E isso significa - talvez a questão mais importante em face das meias verdades que parecem governar a educação global - que se precisa fazer um deslocamento da pura sobrevivência para uma orientação sobre a vida. Não obstante, a sobrevivência implica uma orientação sobre a questão de como se pode adaptar e ajustar às circunstâncias em constante mudança, considerando que a vida provoca para explorar se vale a pena se adaptar às circunstâncias que se apresentam, ou se a primeira tarefa é, na verdade, tentar criar circunstâncias melhores.

\section{DA APRENDIZAGEM AO DESENVOLVIMENTO?}

Todos os apontamentos feitos até agora são, em certo sentido, uma resposta ao entendimento de que educação 
é sobre aprendizagem. Espera-se ter mostrado algumas das limitações do discurso da aprendizagem no que diz respeito à educação. E pontuar que educação diz respeito a desenvolvimento e a formação.

A crítica à ideia da educação como sobrevivência e a defesa de orientar a educação para a vida, e vida significativa, podem ser lidas como argumentos no sentido de que, ao invés de fazer da educação uma máquina de aprendizagem, deve-se focá-la no desenvolvimento da criança - particularmente, nos talentos da criança ou, em uma frase sensivelmente diferente, no desenvolvimento do potencial completo da criança. Afinal de contas, se a ambição não é mais sobrevivência, mas vida significativa, pode-se afirmar que é preciso ter certeza de que todos os talentos disponíveis podem desabrochar e florescer para que as crianças possam realmente atingir seu completo potencial. Embora isso possa soar atraente, pensa-se que essa ideia da ambição da educação também não é livre de problemas.

A afirmação que se deseja fazer aqui tem a ver com o fato de que todo ser humano não apenas tem talentos que contribuirão para uma vida boa e significativa, mas também habilidades que operam em sentido oposto. Analogicamente, ao apenas sugerir que a educação deva focar no desenvolvimento de talentos de crianças e jovens, tende-se a esquecer que desenvolvimento pode dar-se em qualquer direção, e que tanto a moralidade quanto a criminalidade são resultados de processos de desenvolvimento. Isso indica que a educação não pode estar preocupada com talentos, desenvolvimento e potencial em si, mas enfrentar a importante questão de ajudar crianças e jovens a encontrar as aptidões certas, o potencial certo e o desenvolvimento certo, sem querer sugerir, é claro, que o que é "certo" é simples e claro. Ao contrário, não simplesmente deixar florescerem mil flores, mas questionar a todos que estão chegando, de todos os talentos que mostram, se estes são desejáveis para suas vidas e para a vida que se procura viver com os outros em um planeta vulnerável.

Ao invés de pensar a educação como um processo de suporte e promoção, isso indica que a modalidade principal da educação é o da interrupção (ver também BIESTA, 2010). A questão principal que a educação precisa responder é, portanto, se o que se deseja - não apenas em termos do que se quer ter, mas também em termos do que se quer ser - é realmente desejável para a própria vida e para a vida com os outros nesta terra. Essa questão é posterior a certa virada. E a virada que está em jogo aqui é do que se pode chamar de um modo ego-lógico de ser (para o chamado "ego-lógico", ver LEVINAS, 1961, p. 35), um modo de ser no mundo que se centra em torno do ego e de seus desejos, para um modo não ego-lógico de ser. Tal maneira não ego-lógica de ser no mundo não é aquela em que se dominam os desejos, mas aquela em que estes são selecionados, transformados e "rearranjados" (SPIVAK, 2004, p. 526) para que possam sustentar um modo não ego-lógico de ser no mundo.

\section{QUALIDADE DO CRESCIMENTO: UM VALOR EDUCACIONAL}

A ideia de ser no mundo de um modo não ego-lógico é uma formulação mais recente de uma antiga, mas não obstante, crucial ideia educacional, aquela da "qualidade do crescimento". O que se argumenta aqui é, de fato, que a educação deve ter uma orientação para a qualidade do crescimento, porque esta denota um modo de ser no mundo que não é autocentrado, não é dirigido pelos desejos, mas tenta levar em consideração o fato de que se existe sempre com outros em um planeta com sua própria integridade e com suas próprias limitações. Philippe Meirieu (2007) descreveu o que está em jogo aqui quando disse que o sujeito-estudante é o que é capaz de estar no mundo sem ser o centro do mundo - e tal modo de ser descentrado é o que caracteriza a qualidade do crescimento.

Por falar em qualidade do crescimento como um modo de ser, procura-se distanciar da ideia das abordagens de desenvolvimento que, por um longo tempo, têm pensado em qualidade do crescimento como um produto ou resultado de um processo de desenvolvimento. E ainda como um tipo de posse que se supõe "segura" e "garantida", uma vez que se tenha alcançado certo estado ou estágio de maturidade. Não se pensa que esta seja uma forma viável de pensar sobre o que a qualidade do crescimento significa. Talvez, a principal razão para isso seja que há muitas pessoas que passaram por tal trajetória de desenvolvimento sem nunca se comprometer com o que encontram em suas vidas de uma forma adulta $\mathrm{e}$ descentrada. É preciso considerar também que muitos que ainda não passaram por tal trajetória - podemse chamá-los de crianças - revelam-se perfeitamente capazes de se comprometer com o que encontram em suas vidas de uma forma adulta. O que está relacionado com qualidade do crescimento, portanto, não é a idade ou o desenvolvimento, mas como se consegue ou não estar e ser no mundo sem estar colocado no centro deste. Isso porque qualidade do crescimento não é algo que se pode ter, mas permanece como um desafio contínuo ao longo da vida -sempre uma questão aberta sobre como se deve comprometer com a existência em toda nova situação e encontro.

Por esse ângulo, não se pode pensar na escola como a instituição que deve produzir pessoas que serão adultas. É muito mais relevante e importante abordar a escola como um lugar, parcialmente protegido de todas as demandas da sociedade, em que é possível praticar, em todos os 
tipos de meios e formas, o que significa existir no mundo de um modo adulto.

\section{EDUCAÇÃO COMO FORMAÇÃO: TOMANDO-SE ALGO CONCRETO NO MUNDO}

Estar no mundo de um modo adulto, existir de um modo adulto - sem ser o centro do mundo -, pode ser parecido com uma resposta ao que está "fora", que vem ao encontro, que desafia, que chama adiante. Tais encontros são sempre interrupções - nos modos de como se é, nos desejos, nos questionamentos sobre esses desejos, ou seja, se o que se deseja é desejável. Enfrentar essa questão, levantá-la, dar-lhe um lugar, respondê-la, é menos um assunto de aprendizagem e, talvez, mais um encontro com o ensino, com a experiência de ser ensinado, de ser abordado pelo que está fora de si mesmo e não construído por si.

A interrupção que está em jogo aqui não é aquela que procura destruir a criança, mas significa "orientar" a qualidade do seu crescimento, ou seja, "dirigir" para uma maneira diferente do que a atual de ser no mundo. Ação educacional, se for destinada à qualidade do crescimento, não é uma questão de se ajustar para onde a criança está, isto é, para suas necessidades, é sobre uma orientação para o que ainda não há, para o que ainda não tem evidência, mas que pode chegar. $\mathrm{E}$ isso começa a apresentar problemas com a educação que pensa que só pode fazer algo se tiver pleno conhecimento da criança, de onde é, quais seus problemas e necessidades.

Pode-se pensar aqui, por exemplo, na lógica da confiança, em que esta é profundamente necessária nessas instâncias em que não se sabe se o outro pode ser confiável. Nesses casos, é preciso acreditar. Prever como os outros agiriam não é uma questão de confiança, mas de cálculo. Confiar em alguém, mesmo contra tudo presentemente disponível é, nesse sentido, um gesto educacional profundo, pois fornece à criança uma escolha, seja para agir de uma maneira confiável ou não. O que o educador faz aqui é abrir para a criança uma possibilidade para um modo adulto de ser no mundo. Ainda assim, ela tem a liberdade de entrar nessa possibilidade, nessa forma de ser ou não. Precisamente nesse sentido, a interrupção aqui não é destrutiva, mas generativa, embora com um risco fundamental - de que a criança fará o contrário - que não pode e não deve ser afastado ou superado (ver BIESTA, 2014).

O que se encontra aqui, então, não é uma lógica da aprendizagem - de fato, está mais perto de ser uma lógica do ensino -, também não é uma lógica do desenvolvimento porque este é interrompido. Mas é um fundamento da formação, ou seja, de encontrar ou estabelecer uma forma de existência no mundo. No mundo, mas não no centro do mundo, de modo que reste espaço para os outros existirem também.

\section{CONCLUSÃO: O DEVER DE RESISTIR}

Este artigo iniciou-se com a questão sobre o significado da escola. Lentamente, abriu-se caminho a algumas complexidades da educação e também a algumas contradições do discurso contemporâneo sobre a educação. Através disso, reivindica-se a escola como um empreendimento educacional, o que se tem feito à luz da exploração de três respostas para a questão sobre o que a educação deveria ser: aprendizagem, desenvolvimento e formação. Ao fazê-lo, tenta-se dar uma resposta para as três questões.

A primeira é a questão do que é a boa educação. Sugere-se que, no mínimo, uma boa educação deve saber que qualificação não é a única coisa que importa, mas que socialização e subjetivação estão também sempre presentes e precisam ser consideradas. Isso significa que a escola deve ter uma concepção mais ampla de educação, resistindo às contínuas tentativas de reduzi-la apenas à qualificação.

Na segunda questão, aborda-se o que deve importar realmente na educação - qual a sua "preocupação" central. Foram mencionados problemas com relação às noções de aprendizagem e desenvolvimento e levantada a questão para o velho, mas, não obstante, útil, termo da formação. Afinal, a educação deve ajudar crianças e jovens a entrar de uma forma concreta e adulta no mundo, uma forma que torna possível existir nesse mundo sem se posicionar no centro deste. Isso é uma questão de qualidade do crescimento, de um modo não ego-lógico de ser no mundo. Isso foi apresentado como um valor educacional, mas o que se deseja é realçar que esse valor, esse modo de ser no mundo, responde precisamente aos desafios duradouros da vida e da convivência humana: as questões da democracia, da ecologia e do cuidado em responder de um modo adulto e não ego-lógico. Nesse sentido, o interesse da educação na qualidade do crescimento não é algo "específico", "apenas" relevante para a educação e para educadores. Isso responde a um conjunto de questões fundamentais e urgentes da vida contemporânea e futurae novamente a escola deve significar isso e deve resistir às tentativas de manter a educação afastada dessas questões "básicas", que são básicas porque são existenciais e dizem respeito à vida, não à sobrevivência.

Por terceiro, enfim, responde-se à questão sobre qual o lugar que a escola deve ter na sociedade. Ao invés de apenas pensar a escola como uma função da sociedade - embora também o seja -, deve-se manter sempre a possibilidade de que a escola seja um "espaço livre", ainda não completamente determinado pelas demandas da sociedade. Mas um lugar em que praticar é possível, especialmente praticar o que significa existir de um modo adulto no mundo. E isso precisa de muita prática, 
porque não é uma questão de conhecimento, mas, em última análise, de ser e de ser capaz de ser. Tal lugar para praticar é particularmente relevante em um mundo que, não menos importante pelas demandas das formas capitalistas de "fazer" economia, não está realmente interessado na interrupção dos desejos. Ao contrário, estimula que pessoas tenham mais e mais desejos, para que queiram mais e, portanto, comprem mais, para que a economia possa se manter crescendo, e assim por diante. Em um mundo, portanto, que quer que todos permaneçam ego-lógicos, é crucial ter lugares de refúgio em que outros modos de ser e estar juntos possam ser praticados. Aqui, então, talvez esteja a melhor razão para o dever de resistência da escola para defender o valor da qualidade do crescimento em um mundo que muitas vezes prefere manter as pessoas como crianças. Essa tarefa não é insignificante, e está em jogo se realmente se quer que a escola seja um lugar em que a educação possa ocorrer.

Uma questão final a levantar é o fato de "a escola", em si mesma, ser sobretudo uma instituição. O que foi proposto neste artigo é, antes de tudo, endereçado àqueles que fazem a instituição chamada escola acontecer, ou seja, aos professores. Não se tenta apenas indicar o que há para fazer pelos professores, se estão comprometidos com a escola como um empreendimento educacional, mas também realçar algumas complexidades exclusivas do trabalho do professor. Complexidade que exige cuidado, julgamento situado e disposição para se comprometer com a abertura e com o risco que a educação sempre carrega. Enquanto os burocratas podem continuar tentando manter esse risco afastado no (equivocado) pressuposto de que a melhor educação é aquela que é completamente previsível, a educação como um empreendimento humano destinada à qualidade do crescimento de crianças e jovens nunca pode acabar como uma forma de gerenciamento e controle. Precisa, outrossim, de pessoas dispostas a assumir o risco, a arriscar-se a si mesmas para o futuro de modos humanos de existir juntas.

(Traduzido do inglês por BRUNO ANTONIO PICOLI)

\section{REFERÊNCIAS}

BIESTA, G. J. J. Beyond learning: Democratic education for a human future. Boulder: Paradigm Publishers, 2006.

BIESTA, G. J. J. Good education in an age of measurement: ethics, politics, democracy. Boulder: Paradigm Publishers, 2010 .

BIESTA, G. J. J. Interrupting the politics of learning. Power and Education, v. 5, n. 1, p. 4-15, 2013.

BIESTA. G. J. J. The beautiful risk of education. Boulder: Paradigm Publishers, 2014.

BIESTA, G. J. J. Hva er en pedagogisk oppgave? Om det å gjøre voksen eksistens mulig. In: BRUNSTAD, P. O.; REINDAL, S. M.; SÆVEROT. H. (Red.), Eksistens og pedagogikk: en samtale om pedagogikkens oppgave. Oslo: Universitetsforlaget, 2015a. p.194-209.

BIESTA, G. J. J. Wereld-gericht onderwijs: Vorming tot volwassenheid. De Nieuwe Meso, v. 2, n. 3, p. 54-61, 2015 b.

BIESTA, G. J. J. Freeing teaching from learning: opening up existential possibilities in educational relationships. Studies in Philosophy and Education, v. 34, n. 3, p. 229-243, 2015c.

LEVINAS, E. Totality and infinity: an essay on exteriority. Pittsburgh; The Hague: Duquesne University Press; Martinus Nijhoff, 1969.

MASSCHELEIN, J. \& SIMONS, M. Apologie van de school. Leuven: Acco, 2012.

MEIRIEU, P. Pédagogie: le devoir de résister. Issy-lesMoulineaux: ESF éditeur, 2007.

MOLLENHAUER, K. Vergessene Zusammenhänge: Ueber Kultur und Erziehung. München: Juventa. 1983.

OELKERS, J. Reformpädagogik. Eine kritische Dogmengeschichte. 4 ed. München: Juventa, 2005.

SIDORKIN, A. Learning relations: impure education, deschooled schools, and dialogue with evil. New York: Peter Lang, 2002.

SPIVAK, G. C. Righting the wrongs. South Atlantic Quarterly, v. 103, n. 2-3, 523-581, 2004.

Recebido em 19-01-2018

Aprovado em 09-03-2018. 